\title{
A CONSOLIDAÇÃO DA DITADURA NO BRASIL SEGUNDO A VISÃO DE BERNARDO NEUSTADT NA REVISTA ARGENTINA TODO (1964-1965)
}

\author{
Helder Gordim da Silveira ${ }^{1}$
}

\section{Introdução}

O presente artigo resulta de um projeto de pesquisa que busca examinar a repercussão ideológica do Golpe de Estado e do regime ditatorial implantado no Brasil, em 1964, na imprensa informativa empresarial argentina, destacando-se aqui a revista Todo e o papel de seu fundador e diretor, Bernardo Neustadt, na construção das notícias internacionais acerca daquele contexto político brasileiro, direcionadas ao público leitor argentino.

O exame do discurso jornalístico, como forma simbólica entrecruzada, pela construção do sentido, com os sistemas contextuais de poder, embasou-se na perspectiva teórica associada ao conceito de ideologia, atualizado em John Thompson. ${ }^{2}$ Nessa direção, aponta-se para a hipótese básica aqui trabalhada, segundo a qual a construção narrativa-interpretativa das notícias acerca dos acontecimentos que consolidavam a ordem ditatorial no Brasil atuou potencialmente como uma ideologia da solução autoritária, que ocorreria com o golpe de 1966, para a crise sociopolítica argentina.

Situamos aqui, com Pierre Nora, ${ }^{3}$ a progressiva aproximação, inclusive no campo epistemológico, entre a notícia, como categoria jornalística, e o acontecimento, como uma forma essencial de apreensão imaginária do real no mundo contemporâneo.

O lugar institucional de emissão de tal forma discursiva é a aqui denominada "imprensa informativa empresarial", uma referência genérica aos jornais diários e revistas, com forma, conteúdo e natureza organizacional resultantes da transição que se verifica, grosso modo, a partir das décadas finais do século dezenove, com origem marcada nos Estados Unidos e com reflexos imediatos na Europa e na América Latina. Trata-se da passagem de uma imprensa diretamente ligada às disputas ideológicas e partidárias da arena política, para uma atividade social que vinha a reivindicar independência e autonomia em relação àquelas disputas, fundada na perspectiva de profissionalização, de empreendimento empresarial e de objetividade informativa, no plano ideológico. ${ }^{4}$

Tal processo de transição não apresentou, todavia, uma trajetória linear nos países ocidentais, tampouco representou uma ruptura radical entre os modelos jornalísticos mencionados, o que talvez seja o caso paradigmático apenas do jornalismo estadunidense ${ }^{5}$ dando-se de modo bem mais complexo $e$ matizado na Europa e na América Latina, como, por exemplo, no caso francês. ${ }^{6}$

De todo modo, a construção da autonomia do campo jornalístico empresarial e o fortalecimento acelerado de seus capitais econômico e simbólico, parecem ter concorrido para o reforço da reivindicação doutrinária, herdada do século XIX, em torno da assim denominada liberdade de imprensa, identificada tradicionalmente à noção clássica de liberdade de expressão e de informação,

\footnotetext{
${ }^{1}$ Doutor em História das Sociedades Ibéricas e Americanas, pela Pontifícia Universidade Católica do Rio Grande do Sul (PUCRS). Professor Adjunto do Departamento de História da Escola de Humanidades da Pontifícia Universidade Católica do Rio grande do Sul; membro permanente do corpo docente do PPG em História da PUCRS. E-mail: <helders@pucrs.br>.

${ }^{2}$ THOMPSON, John. Ideologia e Cultura Moderna. Teoria Social Crítica na era dos meios de comunicação de massa. Petrópolis: Vozes, 1995, esp. cap1.

${ }^{3}$ NORA, Pierre. "O Retorno do Fato". In: LE GOFF, J. e NORA, P. História: novos problemas. Rio de Janeiro: F. Alves, 2 ed., 1979, p. 179-193.

${ }^{4}$ Sobre duas visões paradigmáticas deste processo de transição, ver: CHALABY, J. O jornalismo como invenção angloamericana. Comparação entre o desenvolvimento do jornalismo francês e anglo-americano (1830-1920). Rio de Janeiro: Media \& Jornalismo, 3V, 2003 e SCHUDSON, M. Descobrindo a Notícia. Uma história social dos jornais nos Estados Unidos. Petrópolis: Vozes, 2010.

${ }^{5}$ SCHUDSON, M. Descobrindo a Notícia.

${ }^{6}$ CHALABY. J. O jornalismo como...
} 
associada ao Estado de Direito moderno e ao espaço público, ${ }^{7}$ situado entre este e o âmbito dito privado da ordem social. Deriva daí o que vamos denominar liberalismo profissional, como posicionamento padrão da imprensa informativa, como ator político complexo, o qual terá de ser discursivamente compatibilizado, no caso aqui em exame, com o apoio, mais ou menos matizado ou limitado, a certas soluções de tipo autoritário, como veremos adiante.

Voltando à centralidade da categoria notícia, em sua relação com o acontecimento, na constituição do discurso jornalístico, aqui interpretado na ótica de seus possíveis efeitos ideológicos, adota-se a posição de Miquel Alsina, segundo a qual

[...] la noticia es la narración de un hecho o la reescritura de otra narración, mientras que el acontecimiento es la percepción del hecho en si o de la noticia. La empresa informativa puede entenderse como una industria que tiene como inputs los acontecimientos y como outputs las noticias.

Entretanto, e fundamentalmente,

[...] hay que puntualizar que un acontecimiento no es una realidad objetiva, exterior y ajena al sujeto perceptor del mismo [...]. Debo recordar que la teoría de la construcción social de la realidad [...] hace referencia a la vida cotidiana. [...] los acontecimientos son 'realidades' históricas determinadas socioculturalmente, como puede apreciarse en la variación histórica que en los mismos se han producido. En la actualidad los mass media establecen unos parámetros para delimitar los hechos que cabe considerar como acontecimientos. ${ }^{8}$

No mesmo sentido, refere Nelson Traquina:

[...] existe um acordo tácito entre os que escolhem esta profissão de jornalista $e$ o leitor/ouvinte/telespectador que torna possível dar credibilidade ao jornalismo: o principal produto do jornalismo contemporâneo, a notícia, não é ficção, isto é, os acontecimentos ou personagens das notícias não são invenção dos jornalistas. A transgressão da fronteira entre realidade e ficção é um dos maiores pecados da profissão de jornalista, merece a violenta condenação da comunidade e quase o fim de qualquer promissora carreira de jornalista. No entanto, dever-se-ia acrescentar rapidamente que muitas vezes essa 'realidade' é contada como uma telenovela, e aparece quase sempre em pedaços, em acontecimentos, uma avalanche de acontecimentos perante a qual os jornalistas sentem como primeira obrigação dar respostas como notícia [...]. Os jornalistas vêem os acontecimentos como 'estórias' (sic) e as notícias são construídas como 'estórias', como narrativas, que não estão isoladas de 'estórias' e narrativas passadas. ${ }^{9}$

Nessa esteira conceitual são aqui examinadas as formas pelas quais a revista Todo noticiou para seu público na Argentina a consolidação da ordem ditatorial no Brasil, em variados gêneros do discurso jornalístico - editoriais, noticiário, entrevistas, reportagens. A análise é centrada na esfera da produção discursiva, embora não se ignore a limitação que essa opção metodológica representa, ao fixar um caráter hipotético, fundado na razoabilidade interpretativa e na franja social presumida de leitores, dos possiveis contextos de recepção.

\footnotetext{
${ }^{7}$ HABERMAS, J. Mudança estrutural da esfera pública: investigações quanto a uma categoria da sociedade burguesa. Rio de Janeiro: Tempo Brasileiro, 1984.

${ }^{8}$ ALSINA, Miquel R. la construcción de la noticia. Barcelona, Buenos Aires: Paidós, 1996, p. 16-17.

${ }^{9}$ TRAQUINA, N. Teorias do jornalismo. Florianópolis: Insular, V1, 2005, p. 19-20. 


\section{Bernardo Neustadt e a revista Todo no jornalismo argentino}

O semanário argentino Todo circulou entre outubro de 1964 e setembro de 1965. A Argentina, então sob o governo de Arturo Illia, da Unión Cívica Radical del Pueblo (UCRP), vivia, desde a deposição de Perón, pela chamada Revolución Librtadora, de 1955, um contexto político marcado pela tutela das Forças Armadas sobre uma ordem formalmente constitucional. A UCRP, a Unión Cívica Radical Intransigente (UCRI), liderada por Arturo Frondizi, e os principais partidos políticos nacionais (socialistas, conservadores, democrata-cristãos) disputavam o poder na órbita federal e nas províncias com o peronismo, o qual, embora proscrito formalmente, prosseguia uma força política ativa $e$ organizada, nos setores sindical e partidário, com a liderança, embora por vezes discutida na militância, o que, de resto, condicionava sua fragmentação progressiva, de seu líder maior, exilado na Espanha. Desse modo, peronismo e anti-peronismo dividiam politicamente o país de forma acentuada. ${ }^{10}$ A Revolução em Cuba atuava como um extraordinário catalisador de tensões, com a radicalização das esquerdas e das direitas, dentro e fora do peronismo e das Forças Armadas, notando-se o surgimento do primeiro foco guerrilheiro em Tucumán, a partir de 1963.

O Exército, sob influência crescente da Doutrina de Segurança Nacional (DSN), dividia-se sobre a questão essencial que envolvia a integração - ou a proscrição repressiva radical - de um "peronismo sem Perón", em uma ordem política estável. ${ }^{11}$

Igualmente recrudescia o conflito prático e doutrinário em torno de modelos de desenvolvimento econômico, fundados na industrialização, de caráter estatizante, ou na agro exportação, de matriz liberal, sobretudo após o governo Frondizi, da UCRI (1958-1962). Este, em aliança com o peronismo proscrito, pusera em prática, até sua deposição pelos militares, uma política desenvolvimentista industrializante, pela via de abertura ao capital estrangeiro e ampla penetração de empresas multinacionais, ${ }^{12}$ de forte repercussão em variadas faces do âmbito sociocultural.

A abertura do país ao mercado internacional, em marcado contraste com a era peronista, refletia-se no cosmopolitismo que passava a marcar ambientes como a Universidade, as manifestações artísticas e o campo editorial e jornalístico. ${ }^{13}$ Neste, especificamente, verificava-se um boom de novas publicações, com destaque para as revistas aos moldes norte-americanos e europeus, sob a égide do chamado Novo Jornalismo e da geração de jovens oriunda dos cursos universitários, no qual se insere a revista aqui analisada.

\footnotetext{
${ }^{10}$ Análises gerais do contexto doméstico argentino podem ser vistas em: CAVAROZZI, M. Autoritarismo y democracia (19552006). Buenos Aires: Ariel, 2009; DE RIZ, Liliana, La política en suspenso 1966/1976, Buenos Aires: Paidós, 2000; DONGHI, T.H. La democracia de masas. Buenos Aires: Paidós, 2000; GAMBINI, H. Historia del peronismo. La Violencia (1956-1983). Buenos Aires: Vergara, 2008; O’DONNELL, G. Contrapuntos. Ensayos escogidos sobre autoritarismo y democratización. Buenos Aires: Paidós, 2004; PARADISO, J. Um lugar no mundo. A Argentina e a busca de identidade nacional. Rio de Janeiro: Civilização Brasileira, 2005; ROMERO, L. A. Breve historia contemporánea de la Argentina. Buenos Aires: Fondo de Cultura Económica, 2001; ROUQUIE, A. Autoritarismos y democracia. Estudios de Política Argentina. Buenos Aires: EDICIAL, 1994.

${ }^{11}$ O Exército, desde 1962, encontrava-se frontalmente dividido entre os grupos azules e colorados, inclusive com enfrentamento armado. Aqueles eram partidários do chamado "frentismo", posição segundo a qual a democracia argentina deveria ser reconstruída com base em um consenso anticomunista entre as forças políticas vivas do país, inclusive um peronismo sem Perón; estes defendiam a implantação de uma ordem política mais diretamente controlada pelo poder militar, com a proscrição permanente e definitiva do peronismo. Sobre os termos políticos dessa divisão e a intervenção militar na esfera política argentina, ver POTASH, R. A. El ejercito y la política en la Argentina 1962-1973. De la caída de Frondizi a la restauración peronista primera parte, 1962-1966. Buenos Aires: Sudamericana, 1994.

${ }^{12}$ Uma análise específica sobre o governo Fondizi e o contexto argentino pode ser vista em LLAIRÓ, M. e SIEPE, R. Frondizi. Un nuevo modelo de inserción internacional. Buenos Aires: EUDEBA, 2003.

${ }^{13}$ Ver a respeito: BERNETTI, Jorge Luís. El periodismo argentino de interpretación en los Años 60 y 70 . El Rol de Primera Plana y La Opinión. IV Congreso ALAIC, Recife, set. 1998; SCIRICA, Elena. Proscripción, modernización capitalista y crisis. Argentina (1955-1966). In: SCALTRITTI, Mabel S. (et al.). Historia argentina contemporánea. Pasados presentes de la política, la economía y el conflicto social. Buenos Aires: Dialektik Editora, 2008; SIRVÉN, Pablo. Perón y los medios de comunicación. La conflictiva relación de los gobiernos justicialistas con la prensa (1943-2011). Buenos Aires: Sudamericana, 2011.
} 
O governo Illia, de base política bastante frágil, ${ }^{14}$ via-se, assim, fustigado pelo debate em torno de uma nova ordem política nacional, sendo geralmente enquadrado em uma imagem de incompetência $e$ lentidão frente às exigências políticas que desafiavam o país. Uma nova ruptura institucional punhase como inevitável no processo de oposição da imprensa ao oficialismo, em um fenômeno caracterizado como golperiodismo por parte de um setor da literatura especializada. ${ }^{15}$

Nesse contexto, apesar do curto tempo de existência e do relativo fracasso empresarial que marca seu desaparecimento, a revista Todo teve expressivo prestígio e relevância entre seu público de classe média e alta, principalmente em função de seu fundador e diretor, Bernardo Neustadt. De larga e polêmica trajetória no campo jornalístico argentino, do qual é um dos nomes exponenciais, até seu falecimento, em 2009, Neustadt, naquele contexto dos anos 1960, fez de Todo sua tribuna de interpelação do campo político e grande "aposta" profissional. ${ }^{16}$

Bernardo Neustadt nasceu a 9 de janeiro de 1925, na Romênia, e emigrou para a Argentina, junto aos pais e ao irmão, Miguel. Aos quinze anos, ao mesmo tempo em que estudava, ingressou na redação do diário El Mundo, passando a trabalhar na seção esportiva do jornal, no qual ganhava um salário mínimo para sobreviver e pagar a pensão onde pernoitava. Simultaneamente, fazia serviços variados de compras e entregas para os funcionários dos jornais Crítica e Notícias Gráficas. Nesse período de juventude, aceitou o convite do então consagrado jornalista esportivo, Estanislao Villanueva, para substituí-lo na revista do Racing, clube de futebol do qual Bernardo era um torcedor fanático. ${ }^{17}$

O 17 de outubro de 1945, princípio da célebre mobilização sindical que libertaria Perón, foi marcante para a vida e a carreira de Neustadt. No dia anterior, fora designado pelo chefe de redação de El Mundo, Enrique Aleman, para ir ao município operário de Avellaneda, com a missão de cobrir as preparações para a manifestação pró-Perón que ali se realizavam. A matéria do jovem jornalista esportivo, que circulou pela redação, valeu-lhe a fama de peronista entre os colegas e chefes e não chegou a ser publicada, pois o jornal aderira à coligação oposicionista Unión Democrática. O episódio revelar-se-ia muito positivo para Bernardo, pois "[...] con Perón en el gobierno, El Mundo se transformó, a la fuerza, en un diario oficialista". E: "[...] así como lo habían relegado a coberturas periodísticas subalternas por creerlo peronista, por la misma razón, Neustadt pasó de cronista deportivo a cronista parlamentario en un periódico que crecía velozmente debido al apoyo del gobierno". ${ }^{18}$

Assim, durante o chamado primeiro peronismo, Neustadt foi um jornalista inteiramente integrado ao regime. Nessa condição, sugeriu ao vice-presidente, almirante Alberto Teisaire, a criação de um organismo semelhante às grandes Confederações apoiadas pelo governo $e$ a ele articuladas, tais como a CGE (Confederación General Económica), a CGP (Confederación General de Profesionales) e a CGU (Confederación General Universitaria), o qual viesse a organizar, junto ao Estado, as pessoas que se reuniam espontaneamente nos bairros populares para jogar bocha ou futebol, as entidades beneficentes, as bibliotecas de bairro, as cooperativas de todo tipo, dentro do espírito corporativo da Comunidad Organizada que propunha Perón. O projeto é aceito pelo vice-presidente e pelo governo e assim, em outubro de 1954, um Decreto Executivo nomeia Bernardo Neustadt como Secretário Geral e diretor geral de relações com as Organizaciones del Pueblo. Ao mesmo tempo, Neustadt exercia a função de porta-voz oficial do Conselho Superior do Justicialismo.

Após a queda de Perón, com a mencionada Revolución Libertadora de 1955, Neustadt passaria inicialmente por grandes dificuldades. Permaneceu preso por vinte dias, sem acusação formal, a mando da comissão especial que investigava o almirante Teisaire. Mais tarde, foi demitido de El

\footnotetext{
${ }^{14} \mathrm{O}$ contexto político do governo Illia pode ser visto em CANTIS, Mario S. La caída de los tres gobiernos radicales. Buenos Aires: Centro de Estudios Unión para la Nueva Mayoría, 1995; LLAIRÓ, Maria de Monserrat (comp.). El Gobierno de Arturo Illia y la Restauración Institucional. Las Relaciones Económicas Internacionales y la Crisis de Gobernabilidad (1963-1966). Buenos Aires: Ediciones Cooperativas, 2007; PANDOLFI, Rodolfo e GIBAJA, Emilio. La Democracia Derrotada. Arturo Illia y su época. Buenos Aires: Lumiere, 2008; SÁNCHEZ, Pedro. La presidencia de Illia. Buenos Aires: Centro Editor de América Latina, 1983.

${ }^{15}$ Ver principalmente a respeito TARONCHER M. A. La caída de Illia. La trama oculta del poder mediático. Buenos Aires: Javier Vergara, 2009.

${ }^{16}$ ULANOVSKY, Carlos. Paren las rotativas. Diarios, revistas y periodistas (1920-1969). Buenos Aires: Emecé Editores, 2005 , p. 230.

${ }^{17}$ TARONCHER, M. A. La caída de Illia..., p. 123.

18 TARONCHER, M. A. La caída de Illia..., p. 124. 
Mundo e sobreviveu trabalhando no Racing e voltando a fazer serviços gerais, como na juventude. Com os recursos da indenização trabalhista, adquiriu a publicação jurídica Gaceta del Foro.

A fase profissional negativa começaria a passar somente em fins de 1957. Na ocasião, seu antigo chefe em El Mundo, Moisés Shebor Jacoby, transferiu-se para o Clarín, que começava a tornar-se um dos grandes jornais argentinos, e convidou-o para assumir a chefia da editoria de Esportes. Rapidamente, Bernardo é transferido da seção Esportes para a Política, onde readquire prestígio e retorna para El Mundo. De volta ao antigo jornal, passa a escrever a coluna "La Crónica Viva", tratando de temas variados, inclusive a política, "[...] que desarrollaba en veinte o treinta líneas, sintéticos e efectistas en lo que será el estilo Neustadt". ${ }^{19}$ Neste período em El Mundo, competia, em estilo e prestígio, com o jornalista especializado em temas políticos, Jacobo Timerman, que então mantinha coluna regular no jornal e que, nos anos 1960, fundaria e dirigiria a revista-modelo Primera Plana $^{20}$ e, logo em seguida, Confirmado, principais concorrentes de Todo, como será visto adiante.

Em 1960, Neustadt fará sua estreia no meio jornalístico em que igualmente se consagrará como referência: a televisão, que dava seus primeiros passos na Argentina, ainda cercada de desconfiança quanto a ser uma moda passageira frente ao todo-poderoso rádio. Seu primeiro programa, no canal 7 , durava cinco minutos, incluindo os comerciais, e se chamava "La Pregunta de Hoy". Escolhia-se um personagem e Neustadt fazia uma pergunta, para uma resposta necessariamente rápida e objetiva do entrevistado.

A partir de agosto de 1961, Bernardo protagonizou uma experiência então inovadora na televisão argentina. Junto à modelo publicitária e locutora Lidia Satragno, a Pinky, apresentava o programa Nosotros. Em um cenário compondo uma sala de estar, o casal recebia convidados - lideranças do sindicalismo, da política, do mundo empresarial, além de altos funcionários públicos - para uma conversa. Após Nosotros sair do ar, Neustadt tentaria repetir a fórmula, dessa vez acompanhado pela também modelo e locutora Mónica Micanovich, com o programa Lo que Nunca se Contó, no qual eram entrevistados empresários de sucesso no pós-guerra, muitos deles imigrantes. A nova experiência, entretanto, fica muito pouco tempo no ar.

A partir de novembro de 1963, começa a ir ao ar no canal 9, de controle estatal, o programa Incomunicados. Nele, Bernardo, novamente acompanhado de Pinky, recebia convidados, desta vez em um cenário expandido, compondo uma casa inteira. Os entrevistados eram recebidos na sala, podiam ir à cozinha tomar café, voltavam para sentar-se na mesma sala ou na biblioteca, para conversar com o casal anfitrião. A fórmula desta vez alcança um sucesso bem maior. Segundo atesta Miguel Taroncher, "Incomunicados alcanzó una audiencia del $63 \%$ en su primera emisión y, a partir de allí, un promedio de $56 \% "{ }^{21}$

A questão diretamente ligada ao surgimento da revista Todo dá-se neste programa televisivo, de Bernardo e Pinky. No princípio de maio de 1964, Neustadt decide convidar o ex-presidente Arturo Frondizi, da oposicionista UCRI. A direção da emissora vetou o convite, alegando que a entrevista com Frondizi seria politicamente inoportuna. $\mathrm{O}$ ex-presidente vinha então fazendo oposição aberta ao governo de Arturo Illia, da UCRP, e defendendo a formação de uma frente nacional, na qual se compusessem variadas forças políticas do país, incluindo a facção azul dos militares e o chamado "peronismo sem Perón", para a implantação de um programa de desenvolvimento industrial acelerado, que não descuidasse do setor agroexportador tradicional.

Inconformado com o veto à entrevista, Neustadt busca e obtém informalmente uma autorização governamental para que esta ocorresse no canal estatal e a direção da emissora acaba por ceder. A "conversa" com Frondizi dura quase 90 minutos, em um programa atípico, no qual entrevistado e

\footnotetext{
${ }^{19}$ TARONCHER, M. A. La caída de Illia..., p. 126.

${ }^{20}$ Criada inicialmente, sob a direção de Jacobo Timerman, para ser veículo da plataforma modernizadora do frentismo defendido pela facção azul do Exército e pelo grupo frondizista, a revista torna-se a principal referência da renovação de forma e conteúdo do discurso jornalístico na Argentina, aos moldes dos grandes semanários internacionais, como a Newsweek estadunidense e a alemã Der Spiegel. Além das obras antes referidas, ver a respeito: TARONCHER, M. A. Un caso de renovación periodística en la Argentina de los años sesenta: La revista Primera Plana. Estudos Ibero-Americanos. Vol XXIV, n. 2, dez 1998; PIÑERO, Elena T. Medios de comunicación y representación política: el caso de Primera Plana (19621966). Temas de Historia Argentina y Americana, n.1, UCA, Facultad de Filosofia y Letras, Nov. 2002; ALVARADO, M. e ROCCO-CUZZI, R. Primera Plana: el nuevo discurso periodistico de la década del '60. Punto de Vista. Revista de Cultura, n.22, dez 1984; MAZZEI, D. H., Primera Plana: modernización y golpismo en los sesenta. Realidad Económica, n. $148,1997$.

${ }^{21}$ TARONCHER. M. A. La caída de Illia..., p. 107.
} 
entrevistadores permaneceram todo o tempo em movimento pelo estúdio, formato inédito na TV argentina. O impacto da edição de Incomunicados é enorme, na audiência e no campo político. De todo modo, esta seria a última edição do programa, bruscamente interrompido pela direção, mesmo com os altíssimos índices de audiência que apresentava. Neustadt tentaria, sem sucesso, o retorno de seu programa, inclusive pela via judicial.

O fim repentino de Incomunicados leva seu principal patrocinador, Mario Alessandro, proprietário da Kenwood, fábrica de eletrodomésticos, a propor para Bernardo Neustadt um novo empreendimento jornalístico: uma revista semanal. A respeito, dirá Bernardo em suas memórias:

[...] una vez que agotamos todos los recursos legales posibles para recuperar el programa me dijo [Mario Alessandro] a la salida de Tribunales:

- El dinero que tenía pautado para publicidad sigue a su disposición.

- Alessandro, usted sabe que no me aceptan en ningún canal.

- Muy bien, pero Kenwwood apuesta a usted en cualquier medio. Personalmente me gustaría acompañar cualquier nuevo emprendimiento periodístico de Bernardo Neustadt.

Juntos resolvimos lanzar una revista política. ${ }^{22}$

Descontados os efeitos memorialísticos de toda ordem, a revista Todo apareceria nos quiosques argentinos em $1^{\circ}$ de outubro de 1964 , mercê da disposição empresarial de Alessandro e da iniciativa do então já consagrado jornalista Bernardo Neustadt. ${ }^{23}$

Desde sua coluna na revista, com caráter editorial, Neustadt exercerá uma clara postura oposicionista com relação ao governo Illia, durante o qual perdera o emprego, conforme visto. $\mathrm{O}$ posicionamento oposicionista - que o levará, de resto, a apoiar o golpe de 1966 - embasava-se ideologicamente em uma linha de pensamento que defendeu no contexto, cujos traços característicos são assim delineados por Miguel Taroncher:

[...] su imagen política en la década del sesenta combinaba un cierto populismo, como parte de su pasado peronista, junto a la propuesta de reformas económicas liberales del nuevo desarrollismo; simpatizaba con sus contactos 'azules' del ejército y con los dirigentes del sindicalismo neoperonista. [...] Todo el abanico de la oposición radical a la gestión de Illía que gestaba el golpe de Estado, se unió e tuvo de referente político al desarrollismo autoritario de Frondizi, quien, luego de su derrocamiento, consideró que los gobiernos, ya fuesen constitucionales o de facto, debían de ser simplemente el medio para alcanzar el desarrollo. [...]. Neustadt, deslumbrado por la capacidad analítica del ex presidente, coincidió con sus postulados de desarrollo económico acelerado y el diagnóstico de la caducidad de la UCRP y el resto de partidos para lograrlo. Desde sus editoriales y en la información sobre el acontecer nacional, vio en la UCRP un obstáculo para impulsar un capitalismo moderno, truncado por el derrocamiento de Frondizi, en $1962{ }^{24}$

Mais especificamente no que toca ao profundo conflito peronismo $\mathrm{x}$ anti-peronismo, que fracionava $e$ instabilizava o sistema político argentino, Neustadt

\footnotetext{
${ }^{22}$ TARONCHER, La Caída de Illia..., p. 110.

${ }^{23}$ Neustadt retornaria à televisão em 1969, durante a vigência da chamada Revolución Argentina, para conduzir o programa de atualidades políticas Tiempo Nuevo, o qual permaneceria no ar ao longo de quase três décadas. Até então, Neustadt dirigiria Todo e, logo em seguida, a revista mensal Extra, com período de circulação também de quase três décadas. Desde os anos 1960, foi igualmente longa e ininterrupta a atuação de Bernardo no rádio. Ao longo de trinta anos, defendeu ali suas posições políticas e entrevistou personalidades de alcance nacional e internacional, tais como Perón, Frondizi, Alfonsín, Salazar, Kissinger, Franco, João XXIII, De Gaulle, Felipe Gonzáles, Fernando Henrique Cardoso, George Bush, Bill Gates, Lee laccoca, entre outros. Ficará marcado em suas relações com o campo político pelo apoio inicial às ditaduras de 1966 e 1976, bem como, a partir dos anos 1980, às políticas públicas chamadas de neoliberais, emprestando respaldo aberto ao governo Menem e ao chamado menemismo (Cf. LLONTO, P. "Hay algún periodista no militante por allí?". Ofícios Terrestres, Facultad de Periodismo y Comunicación Social - Universidad de La Plata, n. 29, s/d; FERNANDES DÍAS, J. Bernardo Neustadt. El hombre que se inventó a sí mismo. Buenos Aires: Sudamericana, 1993; MARINO, S. e POSTOLSKI, G. Relaciones peligrosas. Los medios y la dictadura entre el control, la censura y los negocios. Revista de Economía Política de las Tecnologías de la Información y Comunicación, Vol. VIII, n. 1, en.-abr. 2006.
}

${ }^{24}$ TARONCHER, M. A. La caída de Illia..., p. 128-129. 
[...] propone como solución frente a la ausencia de un tercer partido moderador, la instauración de un bipartidismo de alternancia pacífica, al estilo norteamericano o inglés, que permitiera la construcción de un proyecto nacional, símbolo de la civilización frente a la barbarie de la mutua impugnación y la obstrucción permanente. ${ }^{25}$

Essa "nova legalidade" seria alcançada, segundo a perspectiva a que aderia Neustadt, após um período de intervenção autoritária saneadora e necessariamente pedagógica na relação EstadoSociedade. Conforme vimos propondo, o "liberalismo profissional" do campo jornalístico adaptava-se aos diferentes contextos e se diferenciava em suas especificidades discursivas concretas.

Nessa direção, na primeira edição de Todo, que estampava Charles De Gaulle na capa, então em visita à Argentina, Bernardo Neustadt expõe, em texto especial junto ao sumário, os objetivos fundamentais da nova publicação. O Diretor apresentava sua revista como sendo "[...] coherente, mentalizada, con un objetivo preciso, SER UNA EXPLICACIÓN en medio a tanto tránsito de información" ${ }^{26}$. Colocando-se, assim, na perspectiva ideológica clássica da atividade jornalística moderna, como instrumento chave para a formação legítima de uma assim dita opinião pública ativa $e$ esclarecida, Neustadt enumera os objetivos de Todo:

[...] intentar desvanecer confusiones. Derrotar al escapismo. Luchar [...] contra los formalismos, los prejuicios, las crucifixiones en el bárbaro etiquetamiento nacional. Entronar con la REALIDAD, sin mistificar el mundo que vivimos, la vida que transpiramos. No introducirlo a Ud. lector, a Ud. lectora, en los laberintos intrincados de los misterios fabricados para que nos despistemos y sigamos renegando unos de otros [...]. Estúpida, vacíamente, mientras el espejo de los años nos exhibe empantanados, amortizados, rencorosos siempre. Incapaces de romper la rutina. Aplastados de miedo. Miedo a la derrota, a la muerte. En el fondo, el miedo es el gran padre de la crueldad infinita. ${ }^{27}$

Assim postos e qualificados os objetivos da revista que surgia, certamente significativos em sua generalidade para a franja prioritária de leitores argentinos a que se dirige, Neustadt prossegue, referindo-se de forma mais específica à realidade sociopolítica do país, a partir de um posicionamento típico da imprensa informativa empresarial:

[...] como rechazamos el miedo y la crueldad, tampoco admitimos los EXTREMISMOS. Queremos la evolución culta. Perfeccionar el mundo en que nacimos y donde nos nutrimos de raíces claras y que los políticos han bautizado como de 'occidental y cristiano'. AYUDAR A CONSTRUIR UNA SOCIEDAD MÁS JUSTA. Pero no romper la comunidad a fuerza de negaciones, de estremecimientos falsos. Buscar y hallar la CLASE DIRIGENTE ausente. ${ }^{28}$

Note-se a construção do posicionamento que expurga, pela qualificação negativa de "extremista", os projetos políticos à esquerda ou à direita que impliquem em ruptura supostamente radical com uma ordem social naturalizada, com fundamento no padrão civilizatório "ocidental", a qual deveria ser "aperfeiçoada" e tornada mais "justa" através de uma "evolução culta", pela qual seria fundamentalmente responsável uma elite - classe dirigente -, a ser buscada e encontrada. A imprensa particularmente Todo - é assim posta no espaço público como instrumento fundamental de conexão efetiva destes elementos ideológicos, no que vimos denominando "liberalismo profissional".

$\mathrm{E}$, nesse sentido, o Diretor de Todo posiciona a publicação frente ao capitalismo argentino em seus dois modelos, os quais, no campo político, tradicionalmente apareciam como contraditórios e mesmo em confronto:

\footnotetext{
${ }^{25}$ TARONCHER, M. A. La caída de Illia..., p. 153.

${ }^{26}$ Todo, n. 1, p. 4.

${ }^{27}$ Todo, n. 1, p. 4. Grifos no original.

${ }^{28}$ Todo, n. 1, p. 4. Grifos no original.
} 
[...] vida industrial plena sin conflicto con la estancia. Que no lo hay, que se inventa. Sobran artesanos del desencuentro. Queremos gente consumiendo. Trabajando, si, pero consumiendo. No despertándole el apetito, o los apetitos de la vida moderna, y negándole luego el acceso a ese standart por no arbitrar los medios para conseguir un PAIS EN MARCHA. Vitalmente OCUPADO ${ }^{29}$

A linha editorial da revista aparece, assim, posicionada em um espaço de conciliação possível e absolutamente desejável entre a política industrializante de raiz frondizista e o liberalismo econômico clássico, de corte agrarista. De todo modo, segundo a racionalização assim construída, não se vê, no contexto então presente do país, um governo ou mesmo um Estado capaz de operar como elemento propulsor do capitalismo, notadamente como provedor de meios para a ampliação do emprego e do consumo, o que abre espaço potencial para a defesa de uma alteração tendente a "aperfeiçoar" tal ordem, como se viu acima.

Com essa linha editorial, diretamente associada a seu Diretor, Todo tratava de inserir-se no mercado argentino de revistas de informação, o qual apresentava público consumidor geralmente situado nas classes média e alta, com formação educacional superior, conforme referido. Tal mercado apresentava Primera Plana, de Jacobo Timerman, como referência formal e como veículo de maior sucesso editorial. Neustadt pensava, de resto, em aproveitar a ocasião que então se apresentava, com o afastamento de Timerman da revista-modelo, para posicionar Todo em um possível vazio de mercado deixado pela crise que, esperava, iria ocorrer naquela publicação. O inesperado para Bernardo foi a continuidade do êxito de Primera Plana, sob Ramiro de Casasbellas e a fundação de Confirmado por Timerman, que viria a concorrer diretamente com Todo, como nova revista no contexto.

De toda forma, foi com vistas na concorrência com Primera Plana que Neustadt convidou o jornalista Rodolfo Pandolfi, que compusera a exitosa equipe de Timerman, para a chefia de redação de sua nova revista. Pandolfi, de formação universitária voltada ao jornalismo, que marcava a nova geração emergente nos anos 1960, e com postura anti-peronista à esquerda, tentará, inicialmente, fazer de Todo uma reprodução, a mais fiel possível, de Primera Plana, tarefa para a qual contava com a colaboração, como secretário geral de redação, de Enrique Raab. Ambos, de resto, fariam larga e exitosa trajetória no jornalismo argentino.

Todavia, desde a primeira edição, Neustadt entraria em conflito com sua chefia de redação em torno do que Carlos Ulanovsky reputa "el principal motivo de discusión", o qual "consistía en decir a qué distancia debía colocarse la nueva revista con respecto al modelo Primera Plana" ${ }^{30}$ Criticando a primeira edição, Neustadt, que então viajara à Europa e não acompanhara os trabalhos da redação, teria ironicamente referido a Pandolfi que este se enganara a respeito de quem dirigia a revista: não se tratava de Jacobo Timerman.

De todo modo, o conflito em torno ao estilo predominante na revista marcaria negativamente as edições nas quais se verifica, segundo corrobora Miguel Taroncher, ${ }^{31}$ uma indefinição entre o autoproclamado "estilo Neustadt", direto, objetivo, evitando intelectualismo excessivo, e o estilo newjournalism de Primera Plana - ou de Timerman -, sofisticado e com influência acadêmica $e$ literária. O confronto, negativo para o resultado final das edições, apenas se resolveria com o previsível afastamento de Pandolfi e Raab, a partir do que Todo sairá com as diretrizes estilísticas de seu diretor, o que não significava propriamente uma definição.

O restante do staff da revista de Neustadt estava composto por jornalistas já então importantes no campo, tais como Ulises Barrera, Jorge Miguel Cosuelo, Lidia Bianchi, Marcelo Cosín, Esteban Peicovich, Oscar Delgado, Jorge Andrés Chinetti, Paco Urondo e Paola Urtubey. Estrearam em Todo alguns adolescentes que fariam carreiras de destaque no jornalismo argentino: Rolando Hanglin, Pepe Eliaschev, Pablo Gerchunoff e Milton Roberts. O semanário recebeu várias colaborações de um jovem futuro jornalista, então recém-saído do ensino secundário, Carlos Ulanovsky, autor do livro de importância fundamental para o presente trabalho.

\footnotetext{
${ }^{29}$ Todo, n. 1, p. 4. Grifos no original.

${ }^{30}$ ULANOVSKY, C. Paren las rotativas..., p. 231.

${ }^{31}$ TARONCHER, M. A. La Caída de Illía..., p. 114-117. 
O humor político gráfico ficava a cargo do já consagrado Landrú. O chefe de arte era Leonardo Werenkraut. Havia colaboradores eventuais para temas específicos, tais como Pepe Peña, nos esportes; Juan José Guaresti, que analisava a economia nacional, e José Manuel Saraiva, que escrevia sobre a conjuntura política.

Quanto à estrutura, a revista apresentava as seções permanentes: "Personajes", "Humor", "Argentina Política", "Argentina Gremial", Argentina Económica", "Vida Moderna", "Espetáculos" e "Bibliografia", depois denominada "Libros" e finalmente "Letras".

Por fim, vale a pena reproduzir a síntese de Miguel Taroncher sobre as razões do encerramento da experiência editorial de Todo:

[...] fueron varios los factores que incidieron en su fracaso [...]. La pretensión de tapas culturales para una revista de política y economía remitían al estilo de Primera Plana, que continuaba ejerciendo la supremacía para el público de clase media y alta, dejando fuera de juego a Todo, la que, luego de la renuncia de Pandolfi, se convirtió en un medio escrito sin un perfil periodístico definido como el que había logrado Primera Plana y que trataba de imitar Confirmado, sus dos principales adversarias. Además de estos factores, es necesario tener en cuenta [...] la actitud profesional de Neustadt como director quien: "en la redacción tenía un carácter difícil. No se llevaba bién con los jefes y secretarios. Los volvía locos. A veces quería esto, a veces lo otro. Siempre les estaba cambiando algo" [depoimento de Rolando Hanglin]. ${ }^{32}$

\section{Neustadt, Todo e a Ditadura no Brasil para a Argentina Ler}

O período de publicação de Todo coincide com a vigência, no Brasil, da ordem ditatorial marcada pelas disposições do Ato Institucional número 1 (AI 1). O instrumento destinava-se a fundamentar no plano jurídico o golpe de abril, estabelecendo marcos legais para uma ruptura no sistema político com poder instituinte, a qual se punha, nesse sentido, como Revolução, em um apelo ideológico à tradição ocidental do conceito. No horizonte político próximo, colocavam-se as eleições previstas para 1966 e as possibilidades diversas que assim se punham no cenário político brasileiro.

As narrativas referentes a este Brasil sob a presidência "revolucionária" de Castello Branco que surgem como notícia internacional, reportagem especial ou como referência em posicionamentos de natureza editorial nas páginas de 9 edições de Todo $(22,5 \%$ de um universo de 40 edições examinadas) são marcadas pela ambiguidade. Claramente confrontadas com o contexto crítico da Argentina de Arturo Illia e com a perspectiva política defendida pelo semanário de Neustadt, ou, mais propriamente, pelo Diretor, frente à crise, tais narrativas, por um lado, incorporam o conceito fundamental de Revolução, conjunturalmente compatível com o liberalismo profissional do campo $e$ com sua carga legitimadora da ordem autoritária, supostamente transitória, em implantação, e, por outro, expressam faces negativas e dúvidas essenciais quanto à natureza e aos rumos possíveis do novo regime no país vizinho, postas como paradigmáticas para a América Latina, particularmente para Buenos Aires.

Há cerca de um ano antes do golpe que derrubaria o governo de Artuto Illía, Bernardo Neustadt posiciona-se em Todo acerca do papel e da possível intervenção das Forças Armadas argentinas na crise política por que atravessava o país, estabelecendo comparação com a situação brasileira.

Para tanto, partindo do ponto de vista jornalístico, Neustadt refere que "[...] lo vital es no sorprendernos frente a la revelación y alegar ignorancia" e que "para ello basta con repasar la realidad sin hojarasca, no confundirnos con el señuelo de la información" 33 , sempre embasando o texto na posição de formador potencial de uma suposta opinião pública esclarecida.

Nesse sentido, são estabelecidos três pontos essenciais da "real situação" política que poderiam produzir uma intervenção militar traumática. O diretor de Todo começa a estabelecer o primeiro ponto condenando o "golpismo" como perspectiva política superada e afirmando a institucionalização das Forças Armadas argentinas, as quais "[...] no intervendrán en política. Pero actúan, evidentemente,

\footnotetext{
32 TARONCHER, M. A. La caída de Illía..., p. 122.

${ }^{33}$ El Equipaje de Arena, Todo, n. 6, p. 10. 
de árbitros. Neutrales pero no indiferentes. Un factor de poder que gravitará a la hora del crepúsculo" (grifos no original). ${ }^{34}$

Desposando, assim, a tese clássica do papel político arbitral das Forças Armadas, considerando, talvez, as deposições de Perón (1955) e de Frondizi (1962), o jornalista constrói este primeiro aspecto de seu arrazoado afirmando que apenas dois temas da política nacional retirariam os militares dessa posição institucional supostamente consolidada: primeiramente, a irritação causada pelo que chama de "velho peronismo", o qual advogava o retorno de seu líder do exílio na Espanha e, em segundo lugar, a suposta passividade e inação do governo Illía frente à ameaça representada pelo virtual retorno de Perón.

O governo teria ainda "irritado" sobremaneira o alto oficialato ao aceitar a reincorporação à ativa dos líderes e oficiais "colorados" que haviam sido afastados para a reserva em abril e setembro de 1962. O governo Illía recebia de fato o apoio dessa facção anti-peronista radical do Exército, que, conforme discutido acima, fora derrotada naquelas ocasiões pelos chamados "azules", defensores de uma saída constitucional para a crise e que aceitavam o chamado "peronismo sem Perón", "legalizado, que vote, elija, y sepa convivir sin rasgar sensibilidades". ${ }^{35}$

É assim que Neustadt conclui esse primeiro ponto: "[...] nadie duda, a estas alturas, que frente al Ejército actual no hay resquicio posible para 'la vuelta de Perón'. E, incorporando tal posicionamento ao próprio discurso: "por motivos obvios y porque además no supone pacificación"”. ${ }^{36}$

O segundo ponto com potencial para provocar uma intervenção militar seria constituído pela gravidade da crise econômica e social, aliada ao que se punha como incapacidade do Executivo para enfrentá-la de maneira efetiva. Porém, quanto a este aspecto, os militares não fariam pressão imediata sobre o governo, segundo informa Neustadt.

No terceiro dos pontos mencionados, o jornalista adverte que, no caso de produzir-se intervenção militar pela concretização dos dois pontos anteriormente postos, esta fugiria do caráter arbitral clássico, para converter-se em um novo regime, de corte excepcional, mesmo no caso de tal intervenção produzir-se sob a liderança "azul":

[...] habrá aquí entonces '50 años de gobierno militar y un proceso a todos los dirigentes políticos, peronistas o antiperonistas', según lo expresara no hace mucho, en la intimidad, uno de los generales que más há luchado por una República Constitucional. Y que más teme que su ideal entre en el ocaso. Esto, así, concretamente, es el instante que vivimos. Maquillarlo es inútt. ${ }^{37}$

Seria o general mencionado, Juan Carlos Onganía, futuro líder da Revolución Argentina? De todo modo, importa destacar que a racionalização se conclui e se sustenta pela menção ao grande espelho para a Argentina, no qual seu autor vislumbrou o novo caráter de uma intervenção militar na ordem política:

[...] que cada uno asuma la responsabilidad (...).El Gobierno, el peronismo, el antiperonismo. Aquí puede repetirse 'el caso Brasil', donde Goulart dejó caer a Quadros, Kubistchek dejó suprimir a Goulart; Carlos Lacerda trabajó sigilosa y férreamente para la destitución de los tres, y ahora Goulart, Kubistchek y Quadros constituyen el elenco de 'cadáveres políticos' a los que el general Arthur da Costa Silva, 'el hombre fuerte de Brasil' (ministro de Guerra), acaba de decirles públicamente: 'El gobierno controla la situación. Por muchos años todavía, el que soque la cabeza corre el riesgo de perderla'. Por supuesto incluido Lacerda. ${ }^{38}$

O "caso Brasil" aparecia, assim, em posição exemplar em uma racionalização na qual uma solução autoritária de novo tipo para a crise política adquiria sentido ao ser "explicada" - e, no caso, não apoiada em seus desdobramentos - nos termos do discurso jornalístico, considerando-se a incompatibilidade do liberalismo profissional, constituinte deste, com a sustentação ideológica de

\footnotetext{
${ }^{34}$ El Equipaje de Arena, Todo, n. 6, p. 10. Grifos no original.

${ }^{35}$ El Equipaje de Arena, Todo, n. 6, p. 10

${ }^{36}$ El Equipaje de Arena, Todo, n. 6, p. 10.

${ }^{37}$ El Equipaje de Arena, Todo, n. 6, p. 10. Grifos no original.

${ }^{38}$ El Equipaje de Arena, Todo, n. 6, p. 10. Grifos no original. 
ordens autoritárias convertidas em regimes políticos de longo prazo.

Em novo texto editorial do período examinado, Bernardo Neustadt, tendo em vista as eleições parlamentares marcadas para 14 de março de 1965, pronuncia-se acerca do papel da classe média na crise argentina. Caracteriza, nesse sentido, a situação política do país como uma grande "confusão", com cinquenta partidos disputando as cadeiras no Parlamento, quinze apenas na província de Buenos Aires, o que resultava, segundo o editorialista, em uma dúvida grave no referido eleitorado de classe média sobre em quem votar e mesmo se "votar" seria propriamente "eleger". Nesse quadro, posto como caótico, inscreve-se a classe média argentina como marca da própria nacionalidade:

[...] cada vez que se ha intentado pintar un cuadro optimista del 'caso argentino' se ha recurrido al mismo esquema: 'no tenemos problemas raciales, sociales, y poseemos una gran clase media'. La clase media es nuestro gran caballito de batalla para probar que no somos Bolivia, Chile, Perú, Paraguay, tal vez ni Brasil..$^{39}$

Posta assim como elemento definidor tradicional da nacionalidade, a classe média argentina apresentaria problemas graves de comportamento político, os quais faziam Neustadt problematizar sua real positividade, ou "utilidade", como fator social de uma resolução possível para a crise do país, para além de seu papel tradicional de amortizadora de tensões.

$\mathrm{O}$ primeiro destes problemas seria uma volubilidade política disfarçada de independência. Nesse sentido, a classe média argentina seria "peronista con el peronismo, antiperonista cuando sucumbe el régimen". Afastando-se do operariado e aspirando a viver como a burguesia, sem nunca efetivamente deter os meios materiais para tanto, a classe média nacional apresentaria comportamento sobretudo conservador: "nunca rompe, siempre mantiene la estructura", sendo "muy maniatada por el miedo al cambio". Assim, "todos juntos, si, tratan de conseguir una tumba en la Recoleta. No fueron capaces ni de inventar un cementerio nuevo". 40

Desse modo, segundo o editorialista, tal classe média teria aderido ao poder político, ou concorrido para sustentá-lo, nas últimas décadas da vida nacional argentina, seja em ordens peronistas ou antiperonistas, sempre "abrumándonos de 'slogans', 'la oligarquía', 'el imperialismo', 'los cipayos', 'los entreguistas". Entretanto, "en los últimos dolidos y flagelados 30 años, [...] no quebramos los esquemas que trafican con nuestro estancamiento, ni hicimos un país tan personal como los de la generación del 80". ${ }^{41}$

Parece que Neustadt contribuía assim para constituir a racionalização recorrente no contexto argentino - e regional, com termos nacionais específicos e diferenciados - segundo a qual a "política tradicional", fundada na antinomia peronismo x anti-peronismo, conduzira o país a uma situação econômica e politicamente caótica e, portanto, incapaz de oferecer soluções positivas para os supostos desafios nacionais então presentes. Frente a tal situação, segundo se põe a racionalização, a classe média mantinha sua posição híbrida e vacilante, não sabendo mais para onde conduzir seu voto. Aqui se punha, ao menos potencialmente, no plano da construção do sentido, a necessidade de uma ruptura saneadora neste sistema político tradicional que viesse a reorientar - no sentido do fortalecimento das dinâmicas capitalistas - as forças sociopolíticas vivas do país, fossem estas do campo peronista ou anti-peronista, para o que se contava com o papel interventor arbitral das Forças Armadas, nos termos ideológicos do projeto civil-militar em construção, o qual, de resto, se concretizaria no golpe do ano seguinte, sob a liderança de Onganía.

O conceito de Revolução, já operado ideologicamente no caso brasileiro, certamente aparecia, como vimos propondo, como paradigma para a Argentina. O grande risco, já apontado por Neustadt e pelo liberalismo profissional do discurso da imprensa informativa empresarial - seria tal intervenção saneadora e supostamente modernizadora converter-se em uma ordem autoritária institucionalizada $e$ baseada exclusivamente no poder militar, para onde o exemplo brasileiro parecia estar negativamente apontando, conforme discutido acima.

De todo modo, a classe média deveria ser mobilizada para essa ruptura que se punha sempre como inovadora e revolucionária, segundo sustenta o editorialista:

\footnotetext{
${ }^{39}$ La Clase Media, Todo, n. 22, p. 1. Grifos no original.

${ }^{40}$ La Clase Media, Todo, n. 22, p. 1.

${ }^{41}$ La Clase Media, Todo, n. 22, p. 1. 
[...] habría que empezar a revisar profusamente nuestra clase media. Indagarla. Sacudirla. Claro que es útil, claro que es un termómetro para la vida de un país. Pero cuando tiene definiciones. Cuando sabe lo que quiere. No cuando pregunta: por quién hay que votar? Es que esa clase media está dividida no sólo para elegir, sino para postularse. ${ }^{42}$

Tal construção interpretativa das notícias acerca da consolidação da ordem ditatorial no Brasil, dirigida ao público de classe média argentino, parecia, assim, conter elementos aparentemente contraditórios. Por um lado, a ruptura institucional, ao ser explicada desde o posicionamento jornalístico, adquiria sentido e legitimidade potencial, notadamente como exemplo para a região, sobretudo para a Argentina; por outro, apontava-se para o risco - desde a perspectiva do liberalismo profissional - de tal ruptura desprender-se de seu caráter positivamente saneador e converter-se em uma ordem ditatorial de longo prazo. Essa aparente contradição, todavia, não deixava de fortalecer o potencial ideológico da atuação da imprensa informativa no cenário de crise, ao menos no caso aqui examinado, no sentido de concorrer para a efetivação de uma solução autoritária, a qual viesse a refundar a ordem democrática, sob a égide da erradicação modernizadora da assim posta "política tradicional". Fica por indagar-se acerca dos termos do sucesso de tal estratégia, bem como sobre um certo caráter recorrente que ela assumiria no futuro. 


\section{RESUMO}

O artigo busca examinar a repercussão da consolidação da ditadura no Brasil como notícia internacional na Argentina, através do estudo de caso da revista Todo, fundada $e$ dirigida por Bernardo Neustadt. Desenvolve-se, com base no conceito de ideologia e de construção social dos acontecimentos, a hipótese de que a veiculação de tais notícias, desde a posição e a atuação políticoinstitucional da imprensa informativa empresarial, concorreu para a legitimação da solução autoritária na crise política argentina, apresentando o caso do Brasil como exemplar. Palavras-chave: Imprensa; Ditadura CivilMilitar; Argentina-Brasil.

Artigo recebido em 15 jul. 2018.

Aprovado em 09 set. 2018.

\section{ABSTRACT}

This article seeks to examine the repercussion of the consolidation of the dictatorship in Brazil as international news in Argentina through the case study of Todo magazine, founded and directed by Bernardo Neustadt. Based on the concept of ideology and social construction of facts, the hypothesis is that the dissemination of such news, considering the stance and the political-institutional procedure of the business press, contributed to legitimize the authoritarian solution in the Argentine political crisis, presenting the case of Brazil as an example.

Key-words: Press; Civilian-Military Dictatorship; Argentine-Brazil. 
